Belyavin, G. (1951). J. gen. Microbiol. 5, 197-207.

\title{
Gultural and Serological Phases of Proteus vulgaris
}

\author{
By G. BELYAVIN \\ National Institute for Medical Research, London, N.W. 7
}

SUMMARY: Three phases of Proteus vulgaris, A, B and C, are distinguishable by cellular and colonial morphology, and to some extent serologically. Phase $A$ is the modal form of freshly-isolated strains; it has a uniform bacillary morphology, swarms intermittently on nutrient agar, and forms stable suspensions in $0.85 \%$ saline. Phase B strains, though possessing flagella, are usually non-motile, non-swarming, and highly pleomorphic; usually form unstable suspensions. Phase $\mathrm{C}$ strains are uniformly filamentous, motile, often swarm in a continuous film, and stability in saline varies with the strain.

The somatic surface of phase A strains is characterized by a dominant typespecific antigen, and traces of a non-specific and a possibly strain-specific antigen. In phase $\mathbf{B}$ strains the type-specific antigen is largely lost, and the other two antigens dominate the surface. The antigenic surface of phase $\mathrm{C}$ strains does not differ markedly from that of phase $A$.

The phase variations $A \rightarrow B$ and $A \rightarrow C$ are reversible. Phase $B$ resembles a partially $\mathbf{R}$ form, in which the mouse-virulence is significantly less than that of the parent phase A strain.

The first serological study of colonial variation in Proteus vulgaris is that of Weil \& Felix $(1916,1917)$ in their classical paper describing the $\mathrm{O}$ and $\mathrm{H}$ variants. This was amplified later by Weil $(1920,1923)$ and Felix (1923) who described variations of colonial morphology in the $\mathbf{O}$ strains of $\boldsymbol{P}$. vulgaris. Both authors described a modal colony, and one which was opaque grew more slowly than the modal on nutrient agar at room temperature, and gave a finely granular growth in broth. In addition, Felix described a non-swarming $(O)$ colony which had an irregular or ill-defined edge, and was granular ('griessig'). Although the small-colony variant and the apparently 'normal' type of colony to which it occasionally reverted, differed serologically from the parent 'normal' strain, no association was demonstrated between changes in antigenic constitution and colonial form. Both authors regarded this variation as a specific kind of group transformation, largely because Weil found that his small-colony variant of an X19 strain had developed an antigenic receptor identical with that found in his X2 strains. Felix confirmed this, and regarded many of his variant strains as intermediate stages ('übergangsformen') in this antigenic reconstruction.

Few of the later workers on the morphology and serology of the Proteus group mention colonial or antigenic variation (Taylor, 1928; Moltke, 1927; Varela, Zozaya \& Imaz, 1944; Rustigian \& Stuart, 1945; Perch, 1948), with the exception of Yacob (1932) who redescribed the $O$ and $H$ variants of Weil \& Felix. Rauss (1936), in making an extensive investigation of the $\boldsymbol{P}$. morganii group, pointed out its morphological and antigenic relationships with $P$. vulgaris. He described a granular colony with a rough surface and irregular edge, which formed an auto-agglutinable suspension in $\mathbf{0 . 8 5} \%$ saline and which he regarded 
as Rough; but he did not examine its antigenic constitution. In view of the fact that little systematic study of variation in $P$. vulgaris appears to have been reported, the following observations are recorded.

While making a serological analysis of fifty laboratory strains of $\boldsymbol{P}$. vulgaris originally isolated from infections of the urinary tract and of wounds and burns (Belyavin, Miles \& Miles, 1951), three types of colony were frequently found in cultures on MacConkey's agar, which for descriptive purposes have been designated A, B and $\mathrm{C}$. In this paper $\boldsymbol{P}$. vulgaris indicates both ' $\boldsymbol{P}$. vulgaris Hauser' and ' $\boldsymbol{P}$. mirabilis Hauser'.

\section{Morphology of the $A, B$ and $C$ forms}

Colonial morphology. The colonies were studied on MacConkey's (1905) agar modified by the addition of $0.5 \% \mathrm{NaCl}$.

Colony $\boldsymbol{A}$. The A colony conforms to the text-book description of $\boldsymbol{P}$. vulgaris. After overnight incubation at $37^{\circ}$ it is $3-4 \mathrm{~mm}$. in diameter, colourless, lenticular with either an entire or a finely, radially striated edge and a 'beaten copper' surface. By strong oblique transmitted light, the colony usually has a white brilliance, and under a hand-lens has a laminated structure in the form of concentric rings (Pl. 1, figs. 1, 2). The bacilli in this colony always form heatstable, saline-stable suspensions whose antigenic consitution is classed as typespecific by Belyavin et al. (1951); and may be regarded as the modal $\mathrm{S}$ form.

Colony B. By contrast with A, the B colony is smaller, with a smooth edge, a denser centre due to its conical elevation, and a smooth shiny surface (Pl. 1, fig. 2). By oblique transmitted light it is much more homogeneous than the A colony, is only finely granular and by oblique transmitted light has a dull, dusky appearance simulating the appearance of ground glass (Pl. 1, fig. 2).

Colony $C$. The $\mathrm{C}$ colony always differs strikingly from $\mathrm{A}$ and $\mathrm{B}$. Often larger than the A colony, and flat, its surface is rough, the edge highly irregular, usually dentate or even fimbriate. By oblique transmitted light on MacConkey's agar it is much less refractile than colony $\mathbf{A}$, and is markedly granular (PI. 1, fig. 1).

The colony of the $\mathbf{C}$ form is always readily distinguishable from that of $\mathbf{A}$ and B. It is not always easy, however, to distinguish $\mathbf{A}$ and $\mathbf{B}$, which differ most obviously when examined by oblique transmitted light. By direct transmitted light, or diffuse daylight, except for the difference in size, in a mixture of $\mathbf{A}$ and $\mathbf{B}, \mathbf{B}$ colonies may be easily overlooked. Furthermore, the distinctive morphological characters of the two colony types are affected by the quality of the medium and by the strain. Distinction is often difficult on excessively dry plates and on media with lower concentrations of sodium chloride. Different brands of peptone influence the colony appearance, some enhancing the brilliance of the scattered light, and some the concentric laminae of the $\mathbf{A}$ colony. The internal structure and the relative size of the colonies are the two characters, in that order, which are the most constant.

Cellular morphology. The cellular morphology of the three forms is clear cut on whatever medium they are grown. From MacConkey's agar, the A form consists of a profusion of regular bacillary forms (Pl. 1, fig. 3) about 0.5 $\times 5-6 \mu$., 
in marked contrast to the morphology on the same medium of forms $\mathbf{B}$ and $\mathbf{C}$. $\mathrm{B}$ is highly pleomorphic; filaments, cocco-bacillary forms of varying sizes and curiously misshapen giant forms occur in profusion (Pl. 1, fig. 4), whereas form $\mathrm{C}$ grows in long tangled filaments, $20-40 \mu$. or more in length (PI. 1, fig. 5). Occasionally fusiform or club-like swellings are present on the filaments. The motility and swarming of these forms and their growth in liquid media are also distinctive, though deviations from the modal characters are not uncommon.

On nutrient agar overnight at $37^{\circ}$ the $\mathbf{A}$ form swarms intermittently in the characteristic step-like pattern across an agar surface, and the growth consists of both short and bacillary forms. The B form does not usually swarm, although colonies of the kind described by Weil \& Felix (1917) as 'tröpfchen' are occasionally seen; these are colonies surrounded by a halo of minute droplet colonies scattered over thin, filmy outgrowths. The $\mathbf{C}$ form swarms actively on nutrient agar and frequently gives rise to a uniform film of growth without step formation.

The swarming characters are paralleled by the motility of these organisms in liquid media. Motile strains of $\boldsymbol{P}$. vulgaris are more actively motile in liquid media during the first $8 \mathrm{hr}$. incubation at $37^{\circ}$ than after 18-20 hr., when often only a few sluggishly moving organisms can be seen. In 5-6 hr. cultures at $37^{\circ}$ in $2 \%$ peptone water, the $\mathbf{A}$ form shows many actively motile bacillary and cocco-bacillary forms, the $\mathrm{C}$ form many motile filaments and the $\mathrm{B}$ form predominantly short strings of coccoid forms which are non-motile and remain so after as much as $20 \mathrm{hr}$. incubation. However, in 5-6 hr. the $\mathbf{B}$ forms may spread on nutrient agar, and exhibit motility in young broth cultures. At this early phase the liquid cultures of $\mathbf{B}$ forms are granular with a deposit, but after overnight incubation nearly always become uniformly turbid and indistinguishable from the broth cultures of $\mathbf{A}$ and $\mathbf{C}$ forms, except that the latter show a strong, silky shimmer on shaking.

Biochemical characters. Where possible the biochemical activities of the $\mathbf{B}$ and $\mathbf{C}$ forms were compared with those of the parent $\mathbf{A}$ strain. Fermentation was tested in glucose, lactose, maltose, mannitol, sucrose, salicin, galactose, fructose, dulcitol, xylose, raffinose, arabinose, rhamnose, dextrin and inositol. Tests were also made for production of $\mathrm{H}_{2} \mathrm{~S}$, liquefaction of gelatin, reduction of nitrate to nitrite and of methylene blue, indole formation, Voges-Proskauer and methyl red tests. The $\mathbf{A}$ and $\mathbf{B}$ forms of five strains, and the $\mathbf{A}$ and $\mathbf{C}$ forms of ten strains were tested, and in all cases the biochemical reactions of the $\mathbf{B}$ and $\mathbf{C}$ forms were identical with those of the parent $\mathbf{A}$ forms.

\section{Saline stability of suspensions of the $A, B$ and $C$ forms}

The saline stability of the three variants was tested by the method of Pandit \& Wilson (1932). In a number of cases A, B and C colonies were isolated from the same culture and were ideal for comparison. Otherwise, wherever possible, $\mathrm{B}$ or $\mathrm{C}$ forms were tested in parallel with the parent $\mathbf{A}$ strain. From fifteen stock strains twenty-four strains, variant and modal, were isolated.

The variants were grown on nutrient agar overnight at $37^{\circ}$, the growth suspended in distilled water and divided into three parts; one left untreated, 
one treated for $5 \mathrm{~min}$. with $0.005 \mathrm{~N}-\mathrm{HCl}$ at $37^{\circ}$ (Duncan, 1935) and one centrifuged, resuspended in $96 \%$ ethanol and heated for $90 \mathrm{~min}$. at $56^{\circ}$. Both these manipulations destroyed any flagellar components present. All three suspensions were centrifuged and the deposits resuspended in distilled water in a concentration of $4 \times 10^{9}$ cells $/ \mathrm{ml}$. They were tested in $0 \cdot 3 \mathrm{ml}$. volumes against equal volumes of graded solutions of $\mathrm{NaCl}$, giving final concentrations of $\mathrm{NaCl}$ ranging from $6 \cdot 3$ to $0 \cdot 15 \%$, and the results read after $18 \mathrm{hr}$. at $50^{\circ}$. All untreated and ethanol-treated $\mathbf{A}$ forms were stable over the whole range; in one $\mathbf{A}$ form, $\mathrm{HCl}$ treatment made suspensions unstable in distilled water and $0 \cdot 15-0 \cdot 65 \%$ of saline. The $\mathbf{C}$ forms varied in stability; of eight tested, four were unstable in all concentrations of saline from 0 to $6.3 \%$ in the untreated state, and of these four, two were rendered relatively stable over the whole range by treatment either with $\mathrm{HCl}$ or ethanol. One of the remaining four strains became unstable after treatment with $\mathrm{HCl}$ and the other three were stable under all conditions. The corresponding A forms that were available were fully stable.

Of eight $B$ forms, five were markedly unstable above a saline concentration of $0.3 \%$, all but two being unstable both before and after treatment with $\mathrm{HCl}$. The instability was however completely abolished in every case by heating in ethanol. This phenomenon is probably similar to that observed by White in $\mathbf{R}$ strains of Salmonellae and ascribed by him to the presence of an ethanolsoluble $\mathbf{Q}$ antigen (White, 1927). That some $\mathbf{B}$ forms were stable before treatment with $\mathrm{HCl}$ and unstable afterwards may have been due to the stabilizing action of hydrophilic flagellar material, which is destroyed by the mineral acid. All forms were slightly unstable in distilled water and in saline concentrations up to $\mathbf{0 . 8 5} \%$, the instability being unaffected by ethanol treatment. The reason for this is not known.

The agglutination of $\mathbf{B}$ suspensions was granular, whereas the agglutinations of both treated and untreated $\mathrm{C}$ suspensions was coarsely floccular. The autoagglutinating tendency of $\mathrm{C}$ suspensions seemed to vary directly with the length and number of filaments therein, but no systematic observations were made.

\section{Antigenic characters}

Two sera were prepared in rabbits by immunization with HCl-treated suspensions of the B forms of PR 18 and X19; the titres were $>640$. Ethanoltreated, stable suspensions of all the variants examined in the saline stability tests were tested against them. All the $\mathbf{B}$ suspensions were agglutinated by both sera, five of them to full titre. Neither A nor $\mathbf{C}$ suspensions showed any agglutination except one $A$ form which was agglutinated at $1 / 40$ by one serum. The ethanol-treated suspensions of two forms, however, showed a fine agglutination in all tubes, visible with a hand-lens, including the controls. This was probably due to heat instability, because it was observed in tests with other antisera.

Clearly the $\mathbf{B}$ forms differed in some antigenic component from $\mathbf{A}$ and $\mathbf{C}$ forms. Four $\mathrm{C}$ forms were tested by agglutination and absorption tests against homologous anti-C type and anti-A type sera, using HCl-treated, ethanoltreated and untreated suspensions. The results suggested that these did not 
differ markedly from their parent A strain in either flagellar or somatic receptors. It was noted that $\mathrm{O}$ suspensions of $\mathrm{C}$ variants, when tested by 'pure' absorbed

$O$ sera, still gave a coarse flocculant type of agglutination, appearing within $1 \mathrm{hr}$. at $50^{\circ}$. These investigations were not extensive; for instance, only two anti-C variant antisera were prepared and only the four strains tested. The serological analysis of the $\mathrm{C}$ variant must be regarded as preliminary.

\section{Virulence}

The B forms had some of the characters of 'rough' strains-i.e. instability in saline suspension, pleomorphism and some change of serological specificity (Arkwright, 1921). The comparative virulence of B and A strains was of interest. Five of the stock strains yielded both $\mathbf{A}$ and $\mathbf{B}$ forms, and these five pairs were used for direct comparison of virulence. The strains were subcultured from dry stock and plated, $\mathrm{A}$ and $\mathrm{B}$ colonies selected and seeded with a straight wire into serum broth. After 5-6 hr. incubation, the cultures were centrifuged and resuspended in fresh serum broth to give a concentration of about $100 \times 10^{6} \mathrm{cells} / \mathrm{ml}$. Five graded doses were injected intraperitoneally into each of eight mice weighing 19-21 g. Young broth cultures in the logarithmic growth phase were used so that the viable count was a good estimate of the number of organisms injected. Viable counts were made on MacConkey agar by the method of Miles \& Misra (1938). Regression lines were fitted to the dose-response curves obtained, and the LD50 ratios, and their appropriate standard deviations calculated (Table 1). All the $\mathbf{B}$ variants were significantly less virulent than the parent A strain.

Table 1. The LD50 of $A$ and $B$ forms of five strains of Proteus vulgaris

\begin{tabular}{|c|c|c|c|c|}
\hline Strain & Form & LD50 (millions) & $\begin{array}{c}\text { Ratio of LD50 } \\
\text { B/A }\end{array}$ & $\begin{array}{c}\text { Fiducial } \\
\text { limits of error } \\
(P=0 \cdot 05)\end{array}$ \\
\hline PR 49 & $\begin{array}{l}\mathbf{A} \\
\mathbf{B}\end{array}$ & $\left.\begin{array}{r}43 \cdot 4 \\
>176 \cdot 0\end{array}\right\}$ & 一 & - \\
\hline PR 50 & $\begin{array}{l}\mathbf{A} \\
\mathbf{B}\end{array}$ & $\left.\begin{array}{r}71 \cdot 4 \\
110 \cdot 2\end{array}\right\}$ & $0 \cdot 639$ & $0.41-0.859$ \\
\hline PR 51 & $\begin{array}{l}\mathbf{A} \\
\mathbf{B}\end{array}$ & $\left.\begin{array}{r}95 \cdot 8 \\
159 \cdot 0\end{array}\right\}$ & 0.554 & $0.290-0.795$ \\
\hline PR 52 & $\begin{array}{l}\mathbf{A} \\
\mathbf{B}\end{array}$ & $\left.\begin{array}{l}101 \cdot 6 \\
284 \cdot 1\end{array}\right\}$ & 0.397 & $\begin{array}{cc}0.0 & -0.697\end{array}$ \\
\hline PR 53 & $\begin{array}{l}\mathbf{A} \\
\mathbf{B}\end{array}$ & $\left.\begin{array}{l}193 \cdot 8 \\
321 \cdot 3\end{array}\right\}$ & $0 \cdot 619$ & $0.343-0.857$ \\
\hline
\end{tabular}

The serology of the $B$ forms

Although the $\mathrm{B}$ forms generally proved to be non-motile and non-swarming on nutrient agar, electron micrographs of a young broth culture of a completely non-motile strain showed flagella. Ethanol-treated suspensions were therefore adopted for the study of the somatic receptors of these variants, particularly as such suspensions were completely stable in saline. Since most of the variants were appreciably auto-agglutinable even in distilled water, serological confirmation of the presence of flagellar antigen and its receptor structure was 
not conclusive. A modification of technique may be necessary to accomplish this.

The somatic receptors were more successfully studied. Rabbits were immunized against the five $B$ variants used in the virulence tests. After isolation, these variants were successively plated five times on MacConkey's agar, during which the colonial morphology remained unchanged. The bacilli were washed off $18 \mathrm{hr}$. agar slopes with $96 \%$ ethanol, heated for $90 \mathrm{~min}$. at $56^{\circ}$ and then washed by three centrifugations. They were finally resuspended in distilled water. The approximate concentration of organisms was determined by comparison of opacity with a standard suspension of boiled $\boldsymbol{P}$. vulgaris in an optical comparator. For agglutinations all suspensions were made up in $0.85 \%$ saline to a concentration of $2 \times 10^{9}$ cells $/ \mathrm{ml}$.

Freshly prepared A and B suspensions were agglutinated by their homologous sera to nearly the same titre. But whereas each serum (with one exception) agglutinated its homologous $\mathrm{A}$ strain and no other, the B strains all showed a marked degree of cross-agglutination (Table 2). The cross-agglutination of the

Table 2. Cross-agglutination reactions of $A$ and $B$ suspensions of Proteus vulgaris by anti- $B$ sera

A suspensions

B suspensions

PR49 PR50 PR51 PR52 PR53 PR49 PR50 PR51 PR52 PR53 Titre

$\begin{array}{crrrrrrrrrr}\text { Anti-B serum } & \overbrace{} & & & & & & \\ \text { PR 49 } & 2560 & <20 & <20 & <20 & <20 & 2560 & 160 & 640 & 160 & 80 \\ \text { PR50 } & <20 & 1280 & <20 & 960 & <20 & 160 & 640 & 80 & 640 & <20 \\ \text { PR 51 } & <20 & <20 & 640 & <20 & 20 & 320 & <20 & 640 & 20 & <20 \\ \text { PR52 } & <20 & 960 & <20 & 1280 & <20 & 160 & 480 & 60 & 960 & 40 \\ \text { PR53 } & <20 & <20 & <20 & <20 & 1280 & 80 & 20 & 160 & 160 & 2000\end{array}$

A strains of PR50 and PR 52 was due to the fact that they both belonged to the same somatic type (Belyavin et al., 1951). It is reasonable to suppose that the sera contained two antibodies, specific for two distinct receptors, one typespecific and characterizing each $\mathbf{A}$ strain, and the other predominating in the $B$ variants and having a wide range of cross-reactivity. Obviously both receptors were present to some extent in the $B$ variant, because the sera contained both antibodies. To test this hypothesis further, each serum was absorbed by its homologous $\mathrm{A}$ and $\mathrm{B}$ variant; $1 \mathrm{ml}$. amounts of serum, about 64 times as concentrated as the end-point dilution, were absorbed with $1 \mathrm{ml}$. of decreasing concentration of the two suspensions for $2 \mathrm{hr}$. at $37^{\circ}$. The mixtures were then centrifuged, and the supernatant from each tube tested against both variants (Table 3). The results confirm the hypothesis. All A antibody was removed from the sera by low concentrations of A suspensions, but even the highest concentration $\left(160 \times 10^{9} / \mathrm{ml}\right.$.) failed to remove the $B$ antibody completely. On the other hand, $B$ suspensions removed not only $\mathbf{B}$ antibody but also A antibody, confirming the presence of both antigens in several of the $\mathbf{B}$ forms. In order to examine the cross-agglutinating activity of the pure $\mathbf{B}$ antibody, $20 \mathrm{ml}$. volumes of the five sera diluted $1 / 10$ were absorbed for $2 \mathrm{hr}$. at $37^{\circ}$ with 
homologous A suspension at a final concentration of $10 \times 10^{9}$ cells $/ \mathrm{ml}$., and after centrifuging the supernatants were tested for residual $\mathbf{A}$ and $\mathbf{B}$ antibody (Table 4). The absorbed sera show considerably reduced heterologous titres and a diminution in homologous anti-B titre, which is probably due to absorption of homologous $\mathbf{A}$ antibody, assuming that the $\mathbf{B}$ form carries some $\mathbf{A}$ receptor.

\begin{tabular}{|c|c|}
\hline $\begin{array}{c}\text { Antiserum } \\
(1 / 10) \\
\text { absorbed by } \\
\text { variant of } \\
\text { homologous } \\
\text { strain (PR) }\end{array}$ & $\begin{array}{c}\text { Absorbed } \\
\text { serum tested } \\
\text { against } \\
\text { variant }\end{array}$ \\
\hline 49 & $\mathbf{A}$ \\
\hline 49 & B \\
\hline 50 & $\mathbf{A}$ \\
\hline 50 & B \\
\hline 51 & $\mathbf{A}$ \\
\hline 51 & $\mathbf{B}$ \\
\hline 52 & $\mathbf{A}$ \\
\hline 52 & B \\
\hline 53 & $\mathbf{A}$ \\
\hline 53 & $\mathbf{B}$ \\
\hline
\end{tabular}

Table 3

tr., tr. +, $S_{-}, S_{,} S_{+}, T_{-}, T_{,}=$increasing degrees of trace, 'standard', and total agglutination; $0=$ no agglutination

Table 4

Titres with

\begin{tabular}{|c|c|c|c|c|c|c|}
\hline \multirow{2}{*}{$\begin{array}{l}\text { Antiserum } \\
\text { to strain } \\
\text { (PR) }\end{array}$} & \multirow{2}{*}{$\begin{array}{l}\text { A-variant of } \\
\text { homologous } \\
\text { strain }\end{array}$} & \multicolumn{5}{|c|}{ B-variants of strain (PR) } \\
\hline & & 49 & 50 & 51 & 52 & 53 \\
\hline 49 & $<20$ & 2560 & 20 & 80 & 80 & $<\mathbf{2 0}$ \\
\hline 50 & $<20$ & 40 & 240 & 30 & $<20$ & $<20$ \\
\hline 51 & $<20$ & 160 & $<20$ & 320 & $<20$ & $<20$ \\
\hline 52 & $<20$ & nt & nt & nt & 40 & nt \\
\hline 53 & $<20$ & 40 & $<20$ & 120 & 240 & 240 \\
\hline
\end{tabular}

$\mathrm{nt}=$ no test because of low titre of the antiserum.

The fall in cross-agglutinating titres between $B$ forms after absorption of the sera by A strains which themselves do not show these cross-reactions is, however, more difficult to interpret. The results were confirmed by absorption of these monospecific sera by $\mathbf{B}$ variants. Two of these sera only were used, both having a reasonably high homologous titre after absorption. Each was absorbed with falling concentrations of all five $\mathbf{B}$ forms, and then tested for homologous B antibody. Only the homologous strain absorbed any antibody.

\section{Stability of variant forms}

The strains used for this work were laboratory strains, many of them maintained in stock culture for over ten years, and latterly maintained in the dry state (Stamp, 1947). Nothing is known therefore of the occurrence of the variants described amongst freshly-isolated strains of $\boldsymbol{P}$. vulgaris. B colonies 
were found exclusively amongst the dry stock cultures. Purified $\mathbf{A}$ forms maintained in $\mathbf{0 . 7 5} \%$ agar stabs at room temperature remained unchanged in morphology and antigenic constitution. Similar cultures of B forms, however, frequently produced either typical A colonies, or cells with a definite increase in amount of $\mathbf{A}$ receptor. This change could also be brought about by frequent subculture either in broth or on MacConkey's plates, the process being slower on solid media. The strain PR 49 in particular often showed as much as 40-50\% reversion from $B$ to $A$ colonies after $2-3$ days in agar stabs at room temperature. No quantitative data on this point are available, but these observations suggest that the transition from $\mathbf{B}$ to $\mathbf{A}$ is more frequent than the reverse. The serological tests of $B$ forms also suggest that the content of nonspecific component at the surface may vary, but the velocity and direction of this change is unknown. It is of course possible that the B-antigen complex may arise in type-specific strains masquerading as $\mathrm{C}$ variants.

\section{Naming of the variant forms}

If the $\mathbf{A}$ form of $\boldsymbol{P}$. vulgaris is regarded as modal, and the $\mathbf{B}$ and $\mathbf{C}$ forms as variants from the mode, the change appears to be mainly $A \rightleftarrows B$ and $A \rightleftarrows C$. There is no evidence of the sequence $\mathbf{A} \rightarrow \mathbf{B} \rightarrow \mathbf{C}$ or $\mathbf{A} \rightarrow \mathbf{C} \rightarrow \mathbf{B}$. The variations are reversible; and though the $\mathbf{B}$ form has some of the qualities associated with roughness, it is certainly not a completely or an irreversibly rough variant. In these circumstances the least question-begging names for the forms are phases A, B and C. There is a precedent for somatic phases in Leslie \& Gardner's (1931) use of four phases to describe stages in the antigenic degradation of Haemophilus pertussis; and letters are preferable to numbers, which might suggest a regular sequence of phases, a sequence that was not observed in the A, B and C forms. For convenience, therefore, these forms of Proteus vulgaris are provisionally labelled phase $\mathbf{A}$, phase $\mathbf{B}$ and phase $\mathbf{C}$.

\section{DISCUSSION}

Clearly, $\boldsymbol{P}$. vulgaris can occur in three phases, each characterized by features summarized in Table 5. So far no evidence is forthcoming to suggest that the $\mathbf{A}$ and $\mathbf{C}$ forms differ antigenically, although it is possible that the latter may sometimes carry B antigen. Their relationship poses a number of interesting questions. Several investigators, studying the swarming of $\boldsymbol{P}$. vulgaris on agar, have described an alternation of bacterial morphology during this process (Klieneberger-Nobel, 1947; Kvittingen, 1949). Short bacilli alternate with long filamentous forms as the culture spreads over the surface of the agar. The C variant may conceivably represent an organism which for some reason has lost the ability to undergo this cyclic change and remains predominantly filamentous.

The change of the modal colony into the $\mathbf{B}$ phase is not only related to a change in virulence, but seems also associated with an alteration of antigenic constitution which is clear in general but obscure in detail. The type-specific A phase carries a type-specific antigen. Miles (1951) suggests that this antigen accounts for the toxicity of $\boldsymbol{P}$. vulgaris. It is therefore reasonable to relate the 
Table 5. The characters of the $A, B$ and $C$ phases of Proteus vulgaris

\begin{tabular}{|c|c|c|c|c|c|c|}
\hline \multirow[b]{2}{*}{ Phase } & \multirow[b]{2}{*}{ Morphology } & \multirow[b]{2}{*}{ Mobility } & \multirow[b]{2}{*}{ Swarming } & \multicolumn{3}{|c|}{$\begin{array}{l}\text { Stability in } 0.85 \% \\
\text { saline after treatment } \\
\text { with }\end{array}$} \\
\hline & & & & Nil & $\mathbf{H C l}$ & Ethanol \\
\hline $\mathbf{A}$ & Uniform bacillary & + & Step-like & $\mathbf{S}$ & $\mathbf{S}$ & $\mathbf{S}$ \\
\hline $\mathbf{B}$ & $\begin{array}{l}\text { Pleomorphic cocco- } \\
\text { bacillary chains } \\
\text { 'giant'-forms }\end{array}$ & - & Usually nil & (S) & $\mathbf{U}$ & $\mathbf{S}$ \\
\hline C & Uniform filamentous & + & $\begin{array}{l}\text { Often in a } \\
\text { uniform film }\end{array}$ & (S) & $(\mathbf{S})$ & (S) \\
\hline
\end{tabular}

diminished virulence of the $\mathbf{B}$ phase to a partial or complete loss of this factor. Whether this is a true loss, with exposure at the cell surface of a new determinant, or a replacement of one by the other, cannot be decided by these investigations. The structure of the antigen appearing in the $\mathrm{B}$ phase is uncertain. At first it appeared to be a homogeneous antigen with a diminished group-specificity. The absorption and cross-agglutination tests with B forms suggest more a heterogeneous antigenic surface on these strains. That is, two new antigens are uncovered in the $\mathbf{B}$ variant, besides the small amount of A antigen that may still be present. It must be assumed that one of these determinants has so low an antigenic specificity that antibodies to it not only react with similar determinants in a wide range of other strains but also retain some absorptive (or other reactive) affinity for the homologous $\mathbf{A}$ antigen and those of other strains. The other confers on the organism a new and narrow specificity. The hypothetical antigenic structures of the two phases may be represented as in Fig. 1. It is possible that the non-specific component reacts with similar components in other bacterial species, since Proteus strains have been described which have receptors in common with Salmonella strains (Maccolini, 1940). Alternatively, this antigenic component may be widespread among certain groups of organisms. Only a small number of variants were examined, and it is quite possible that all the antigenic components of the $\mathrm{B}$ variant may be heterogeneous. The small-colony variants described by Felix (1923) may have been B variants. Felix \& Rhodes (1931) described them as unstable in saline. The apparent relationship between small-colony variants of an OX19 strain and a normal OX2 strain (Weil, 1923) may be explained by the fact that the OX2 strains used, themselves carried non-specific antigenic receptors. Certainly some OX2 strains from the National Collection of Type Cultures were markedly unstable in suspension, although I have not tested them for the presence of this receptor. The variant described by Maccolini (1940) produced a small colony, but it was isolated on Wilson \& Blair's, not MacConkey's medium, and so may not be comparable. Maccolini states that it was not agglutinated by trypaflavine and was stable in $\mathbf{0 . 8 5}$ and $2.0 \% \mathrm{NaCl}$. This latter test was carried out on living motile suspensions, in which the flagella may have had a stabilizing effect. It was clear, however, that boiled 
suspensions used for the serology were also fully stable, and in my hands true $B$ variants were rarely entirely stable after boiling.

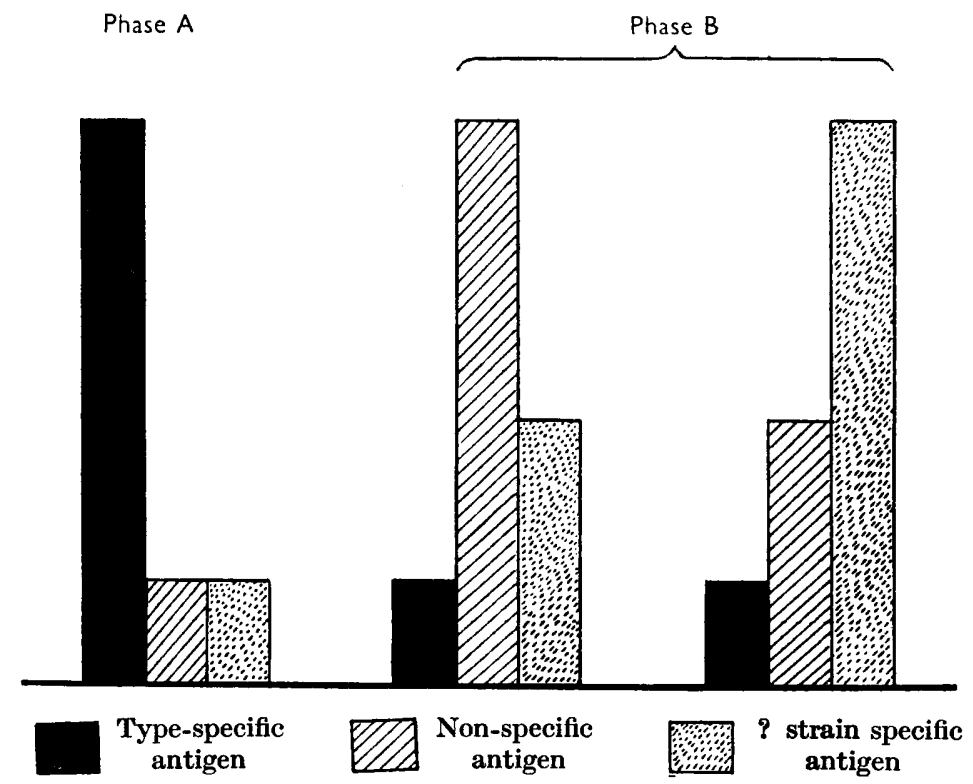

Fig. 1. Diagram of the surface antigens of phases $A$ and $B$ of $P$. vulgaris

The variation $A \rightarrow B$ shows most of the characters of a partial $S \rightarrow R$ variation. It was possible, in spite of the fact that all suspensions used were treated with ethanol, that the $\alpha$-antigen (Stamp \& Stone, 1944) may play some part; but all five of the $B$ suspensions failed to agglutinate with an anti- $\alpha$ serum, and it is safe to say that in these cases the phase $\mathbf{B}$ antigen complex is not homologous in any of its parts with the $\alpha$-antigen.

My thanks are due to Dr W. L. M. Perry for the statistical calculations, to Mr F. Welch and Mr Young for the photographs; and Lt.-Col. H. J. Bensted for the anti- $\alpha$ serum.

\section{REFERENCES}

ARkwвight, J. A. (1921). Variation in bacteria in relation to agglutination both by salts and by specific serum. J. Path. Bact. 24, 36.

Belyavin, G., Miles, E. M. \& Miles, A. A. (1951). The serology of fifty strains of Proteus vulgaris. J. gen. Microbiol. 5, 178.

Duncan, J. T. (1935). Inactivation of the ' $H$ ' antigen, by dilute mineral acid. Brit. J. exp. Path. 16, 405.

Felix, A. (1923). Über Varianten der Proteus X Stämme. Z. ImmunForsch. 35, 57. Felix, A. \& Rhodes, M. (1931). Serological varieties of Typhus Fever. J. Hyg., Camb., 31, 225.

KLIENEBERGER-NobeL, E. (1947). Morphological appearances of various stages of B. proteus and B. coli. J. Hyg., Camb., 45, 410.

Kvittingen, J. (1949). Studies of the life-cycle of Proteus Hauser. Acta path. microbiol. scand. 26, 24. 

Journal of General Microbiology, Vol. 5, No. 1
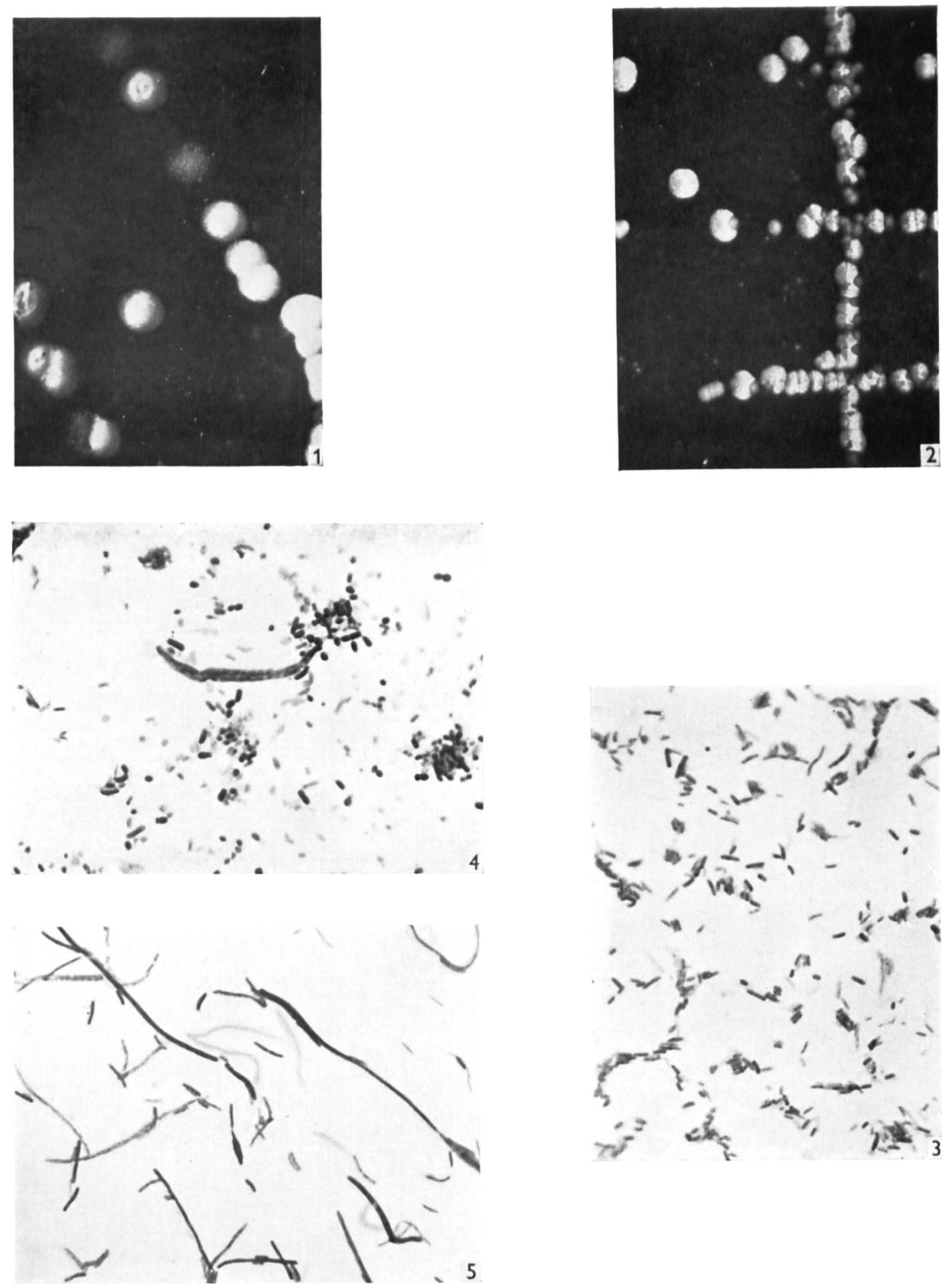

Figs. 1-5

G. Belyavin-Phases of Protevs vulgaris. Plate 1 
Leslie, P. H. \& Gardner, A. D. (1931). The phases of Haemophilus pertussis. J. Hyg., Camb., 31, 423.

Maccolinr, R. (1940). Über einen Neuen in einigen Bact. Proteusstämmen beobachteten Dissoziationstyp. Z. ImmunForsch. 97, 127.

MacConkey, A. (1905). Lactose fermenting bacteria in faeces. J. Hyg., Camb., 5, 333.

Miles, A. A. (1951). The mouse pathogenicity and toxicity of Proteus vulgaris. J. gen. Microbiol., 5. (In the Press.)

Miles, A. A. \& Misra, S. S. (1938). The estimation of the bactericidal power of the blood. J. Hyg., Camb., 38, 732.

MoLTKE, O. (1927). Contributions to the Characterization and Systematic Classification of B. proteus vulgaris (Hauser). Copenhagen: Levin and Munksgaard.

Pandit, S. R. \& Wilson, G. S. (1932). The relation between specific and non-specific agglutination in the Brucella group. J. Hyg., Camb., 32, 45.

Perch, B. (1948). On the serology of the Proteus group. Acta path. microbiol. scand. $25,703$.

Rauss, K. F. (1936). The systematic position of Morgan's bacillus. J. Path. Bact.42, 183.

Rustigian, R. \& Stuart, C. A. (1945). Biochemical and serological relationships of organisms of genus Proteus. J. Bact. 49, 419.

Stamp, Lond (1947). The preservation of bacteria by drying. J. gen. Microbiol. 1, 251.

Stamp, LoRD \& Stone, D. M. (1944). An agglutinogen common to certain strains of lactose and non-lactose fermenting coliform bacilli. J. Hyg., Camb., 43, 266.

TaXlor, J. F. (1928). B. proteus infections. J. Path. Bact. 31, 897.

VARELA, G., Zozaya, J. \& Imaz, F. (1944). Structural and serological analysis of intestinal group of Proteus. Rev. d. Inst. salub. y enferm. trop. $5,15$.

WEIL, E. (1920). Über Varianten des Stammes X19. Wien. klin. Wschr., 33, 61.

WEIL, E. (1923). Variationsuntersuchungen bei X19. Z. ImmunForsch. 35, 25.

Weil, E. \& Felix, A. (1916). Zur serologischen Diagnose des Fleckfieber. Wien. klin. Wschr. 29, 33.

WeIL, E. \& Felix, A. (1917). Weitere Untersuchungen über das wesen Fleckfieberagglutination. Wien. klin. Wschr. 30, 1509.

White, P. B. (1927). On the relation of the alcohol soluble constituents of bacteria to their spontaneous agglutination. J. Path. Bact. 30, 113.

Yасов, M. (1932). Studies of genus Proteus. Indian J. med. Res., 19, 787.

\section{EXPLANATION OF PLATE}

Fig. 1 P. vulgaris. Twenty-hour-old phase A and C colonies, on MacConkey agar, by oblique transmitted light. $(\times 4$.

Fig. 2. P. vulgaris. Twenty-hour-old phase $A$ and $B$ colonies, on MacConkey agar, by oblique transmitted light. In the confluent growth, colonies in the two phases appear as a mosaic. $(\times 2$.

Figs. 3-5. P. vulgaris. Twenty-hour on MacConkey agar. Methylene blue stain. Phase A phase $\mathrm{B}$ and phase $\mathrm{C}$ strains respectively. $(\times \mathbf{9 5 0}$.)

(Received 20 April 1950) 